\title{
INTERNAL CAROTID ARTERY OCCLUSION IN A CHILD
}

\author{
BY \\ S. A. MELLICK and P. D. PHELAN* \\ From the Princess Alexandra Hospital, Brisbane, and Department of Child Health, \\ University of Queensland, and Brisbane Children's Hospital, Brisbane, Australia
}

(RECEIVED FOR PUBLICATION SEPTEMBER 10, 1964)

Occlusion of the internal carotid artery is a rare condition in children. Mymin (1960) and Wisoff and Rothballer (1961) reviewed a total of 24 cases in children under the age of 10 years. Till and Hoare (1962) published carotid arteriograms of 3 children who presented with acute hemiplegia but they gave no additional clinical details. Brandt (1962) also mentioned a case of acute infantile hemiplegia due to internal carotid stenosis. Faris, Guth, Youmans, and Poser (1964) reported the case of a 7-year-old girl who presented with a left hemiplegia due to occlusion of the right internal carotid artery.

The following case is reported because of the comparative rarity of the condition, and in addition because it seems to be the first in which the pathology was demonstrated surgically and found to be amenable in part to corrective surgery.

\section{Case Report}

L.K. was born in 1957 following a normal pregnancy and uncomplicated confinement, birth weight being $7 \mathrm{lb} .2 \mathrm{oz} .(3 \cdot 2 \mathrm{~kg}$.). He was the seventh child in a family of eight. His parents and sibs are perfectly well and there is no family history of febrile convulsions or epilepsy.

The child was well until August 1961 when he was found unconscious in bed. He recovered consciousness fully within a few minutes. His parents did not notice any twitching and there was no incontinence. He was admitted to the Brisbane Children's Hospital and was found to have an upper respiratory tract infection with an associated fever. Physical examination at that stage did not reveal any abnormalities. Carotid artery pulses were not commented upon at that admission.

He remained well until December 1962 when, following a minor disagreement with his mother, without warning he fell to the floor and was found to be unable to move his left arm or left leg. He could not speak but he did not lose consciousness and he seemed to understand what was said to him. No twitching was observed. The weakness lasted about ten minutes and then disappeared spontaneously, and speech returned. Twenty-four hours later

\footnotetext{
* Present address: Royal Children's Hospital, Melbourne, Victoria,
} Australia. there was an identical episode again following minor conflict with parental discipline.

Over the next two months the child had about 10 further similar episodes. He seemed to have some indication that they were coming on as he would run to his parents and indicate that he was afraid just before the onset of the paresis. In at least some of the attacks there was a degree of weakness of the left facial muscles. During this period, the child began to complain of right frontal headache of sufficient severity to make him cry; the headaches did not appear to be associated with the attacks of weakness. Otherwise he enjoyed good health and indulged in normal activities for his age. He started school in January 1963.

He was first seen in the Neurology Department of the Brisbane Children's Hospital in February 1963. At this stage his right carotid pulse was noted to be considerably weaker than his left and a bruit could be heard over his right carotid artery and in his right frontal and temporal regions. There was a minor degree of weakness of the left leg and the left Babinski response was positive. No other neurological abnormalities were detected.

Further review of his past history at this stage revealed the fact that at the age of 3 months a superficial furuncle had been incised over his right mastoid region. In August 1960, he had fallen seven feet onto a concrete floor as a result of which he received minor abrasions to the face. There were no abrasions to the right side of the neck. The child was not subject to tonsillitis or cervical lymph node inflammation.

Further investigations were carried out at that stage. Skull radiographs showed slight underdevelopment of the right side. A right carotid angiogram demonstrated good filling of the external carotid artery and its branches but the intracranial branches of the right internal carotid artery did not fill and the cervical portion gradually tapered off (Fig. 1). In the left carotid angiogram there was reasonable cross-filling of the right anterior and middle cerebral arteries. An electroencephalograph showed some focal disturbance towards the posterior pole of the left cerebral hemisphere but no other local abnormality. No significant asymmetry or focal abnormality of the wave pattern developed during barbiturate-induced sleep. Other investigations were normal. In particular, serum cholesterol was $186 \mathrm{mg}$./ 


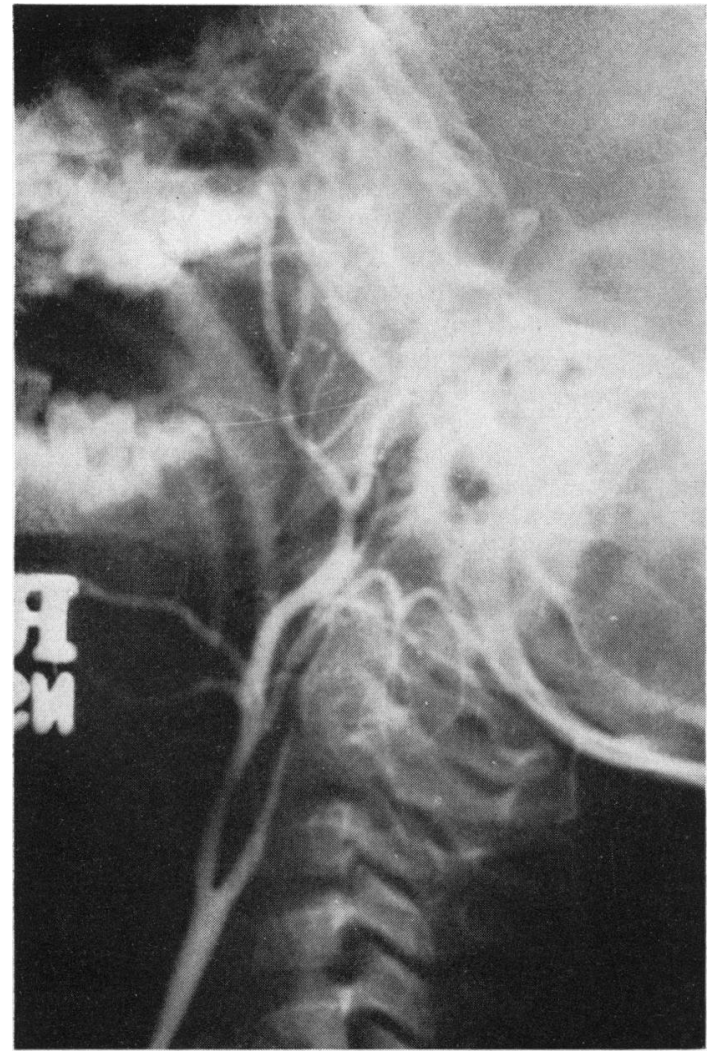

FIG. 1.-Right carotid angiogram.

$100 \mathrm{ml}$., cerebrospinal fluid was normal, and serological tests for syphilis were negative on blood and CSF.

Despite the confirmation of right internal carotid artery occlusion, it was decided to observe the child and treat him with anticonvulsants, as it was considered that the attacks of hemiparesis might have been dysrhythmic in origin. During this time his left Babinski response became negative but minimal weakness persisted in his left leg. However, he did have further attacks of left hemiparesis of short duration.

Four months later he was readmitted to hospital following a period of left hemiparesis lasting half an hour. On this admission he had weakness and hypotonia of his left upper and lower limbs and his left Babinski response was again positive. While in hospital he continued to suffer from severe right frontal headaches and had almost daily periods of hemiparesis. Because of the fear of further deterioration with the possibility of permanent hemiplegia, it was decided to explore surgically his right internal carotid artery.

An operation was performed in June 1963 under general anaesthesia administered through a cuffed endotracheal tube. The right carotid bifurcation was exposed. The right common carotid artery seemed slightly smaller than expected and an atheromatous

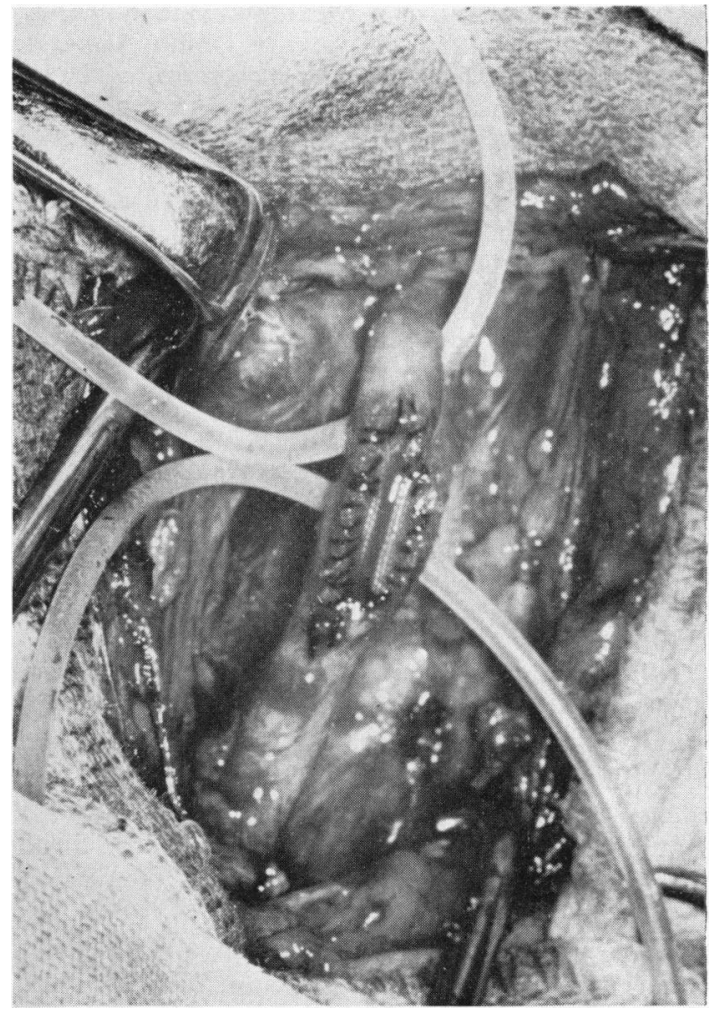

FIG. 2.-The internal carotid artery widened with 'dacron' cloth.

plaque was palpable and visible within the wall of the proximal centimetre of the internal carotid artery. Beyond this, the internal carotid artery was about $2 \mathrm{~mm}$. in external diameter. The leash of vessels and nerves joining the carotid crutch was displayed, and after infiltration with $1 \%$ xylocaine, these were divided in order to produce carotid sinus and carotid body denervation.

An arteriotomy was performed through the region of the plaque and the lesion was inspected from within the lumen. The yellowish white plaque showed up clearly through the overlying intima and could be distinguished readily from the adjacent normal tissue. Endarterectomy was not performed because of the very thin state of the adjacent vessel wall and the absence of a well-marked plane of cleavage outside the atheromatous plaque. The plaque itself extended for about $1 \mathrm{~cm}$. in a longitudinal direction in the vessel and caused considerable narrowing of the lumen at that site. The back-flow from the distal internal carotid artery was poor. The arteriotomy wound was closed with a patch graft of 'dacron' cloth $10 \times 2 \mathrm{~mm}$. (Fig. 2), and this produced an immediate widening of the vessel beyond this site when the clamps were removed and it was felt that an increased blood flow had been achieved.

After the operation, the child continued to have transient attacks of left hemiplegia, but these have been 
much less frequent and of shorter duration than immediately before operation. About five months later, he started to have occasional clonic movements of the left arm and left leg, and about this stage it was noted that the tendon reflexes on his left side were more active than on his right. The headaches have not recurred. The bruit over the right carotid artery persists but it is not as marked and there has been improvement in the strength of pulsation of the right carotid artery but it is still weaker than the left. The electroencephalograph has remained unchanged.

Phenytoin started before operation has been continued and sulthiame (Ospolot) added as it was considered that there was permanent cortical damage as a result of ischaemia, and that the periods of hemiplegia and clonic movements might in part have arisen from an epileptic focus in the damaged area. The frequency of the attacks decreased following the addition of sulthiame.

\section{Discussion}

This child differs from all previously reported cases of childhood carotid artery occlusion. In no other case has an apparently typical atheromatous patch been the underlying cause. Previous cases have followed injury in the region of the soft palate (Braudo, 1956; Fairburn, 1957), severe throat infection (Litchfield, 1938), thrombosis of a patent ductus arteriosus (Gross, 1945; Mymin, 1960), and have been attributed to calcification of the arterial wall (Duffy, Portnoy, Mauro, and Wehrle, 1957), but in the majority no definite pathology could be found. In the middle-aged and elderly the common cause of internal carotid artery occlusion is atheroma, and these cases usually present with a history of intermittent disturbance of cerebral function. The child reported here thus presented with a history similar to that seen in adults and unlike that in the previously reported children, who usually presented with hemiplegia of sudden onset which persisted for days until either death or slow and usually incomplete recovery occurred. Atheroma is very rare in children, particularly in the absence of hypercholesterolaemia.

Surgical intervention in this case seems to have altered for the better what appeared to be a progressive deterioration. However, there is some permanent damage to cerebral function and there would still seem to be reduced flow in his right internal carotid artery. His long-term prognosis must remain uncertain.

The authors would like to thank Dr. D. C. Fison, Medical Superintendent, Brisbane Children's Hospital, Professor T. J. Rendle-Short, and Dr. John M. Sutherland under whose care this child was at the Brisbane Children's Hospital for permission to publish this case.

\section{REFERENCES}

Brandt. S. (1962). Causes and pathogenic mechanisms of acute hemiplegia in childhood. In Acute Hemiplegia in Childhood, ed. M. Bax and R. Mitchell, p. 7. Heinemann, London.

Braudo, M. (1956). Thrombosis of internal carotid artery in childhood after injuries in region of soft palate. Brit. med.J., 1, 665.

Duffy, P. E., Portnoy, B., Mauro, J., and Wehrle, P. F. (1957). Acute infantile hemiplegia secondary to spontaneous carotid thrombosis. Neurology (Minneap.), 7, 664.

Fairburn, B. (1957). Thrombosis of internal carotid artery after soft-palate injury. Brit. med.J., 2, 750.

Faris, A. A., Guth, C., Youmans, R. A., and Poser, C. M. (1964). Internal carotid artery occlusion in children. Amer. J. Dis. Child., 107, 188.

Gross, R. E. (1945). Arterial embolism and thrombosis in infancy. ibid., 70, 61 .

Litchfield, H. R. (1938). Carotid artery thrombosis complicating retropharyngeal abscess. Arch. Pediat., 55, 36.

Mymin, D. (1960). Carotid thrombosis in childhood. Arch. Dis. Childh., 35, 515.

Till, K., and Hoare, R. D. (1962). Cerebral angiography in investigation of acute hemiplegia in childhood. In Acute Hemiplegia in Childhood, ed. M. Bax and R. Mitchell, p. 69. Heinemann, London.

Wisoff, H. S., and Rothballer, A. B. (1961). Cerebral arterial thrombosis in children. Arch. Neurol. (Chic.), 4, 258. 